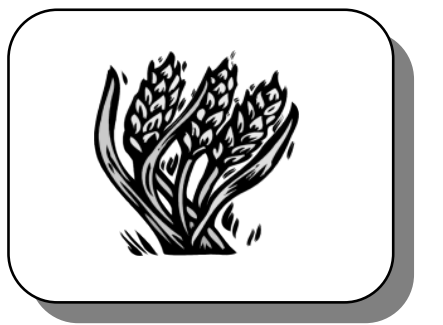

УДК 633.853:631.81:632.934

DOI: $10.36718 / 1819-4036-2020-3-3-10$

\section{АГРОНОМИЯ}

Л.П. Байкалова, А.В. Бобровский, А.А. Крючков

\title{
ВЛИЯНИЕ МИНЕРАЛЬНЫХ УДОБРЕНИЙ И СРЕДСТВ ЗАЩИТЫ РАСТЕНИЙ НА ЭЛЕМЕНТЫ СТРУКТУРЫ И УРОЖАЙНОСТЬ ЯРОВОГО РАПСА
}

\author{
L.P. Baykalova, A.V. Bobrovsky, \\ A.A. Kryuchkov
}

\section{THE INFLUENCE OF MINERAL FERTILIZERS AND PLANT PROTECTION MEANS ON THE STRUCTURE ELEMENTS AND SPRING RAPESEED PRODUCTIVITY}

Байкалова Лариса Петровна - д-р с.-х. наук, проф. каф. растениеводства, селекции и семеноводства Красноярского государственного аграрного университета, г. Красноярск.

E-mail: kos.69@mail.ru

Бобровский Александр Владимирович - канд. с.-х. наук, вед. науч. сотр. отдела агротехнологий Красноярского НИИ сельского хозяйства ФИЦ КНЦ СО РАН, магистрант каф. общего земледелия и защиты растений Красноярского государственного аграрного университета, г. Красноярск. E-mail: aleksandr_bobrovski@mail.ru

Крючков Александр Анатольевич - ст. науч. сотр. отдела агротехнологий Красноярского НИИ сельского хозяйства ФИЦ КНЦ СО РАН, г. Красноярск. E-mail: kralanat@yandex.ru

Цель исследований - изучение влияния минеральных удобрений и средств защиты растений на элементы структуры урожая и урожайность ярового рапса в условиях Красноярской лесостепи. Задачи исследования: 1) оценить схемы защиты ярового рапса «Агрокемикал ДФ» и «Сингента» по следующим фонам: без применения удобрений; аммиачная селитра $N_{80}$; аммиачная селитра + аммофос $\mathrm{N}_{80} \mathrm{P}_{80}$; азофроска $\mathrm{N}_{80} \mathrm{P}_{80} \mathrm{~K}_{80}$; 2) оценить влияние минеральных удобрений по системам защиты растений "Агрокемикал ДФ» и «Сингента».
Baykalova Larisa Petrovna - Dr. Agr. Sci., Prof., Chair of Plant Growing, SelectionandSeedFarming, Krasnoyarsk State Agrarian University, Krasnoyarsk.E-mail: kos.69@mail.ru

Bobrovsky Alexander Vladimirovich - Cand. Agr. Sci., Leading Staff Scientist, Department of Agrotechnologies, Krasnoyarsk Research and Development Institute of Agriculture of FRC KRC SB RAS, Magistrate Student, Chair of General Agriculture and Plants Protection, Krasnoyarsk State Agrarian University, Krasnoyarsk.

E-mail: aleksandr_bobrovski@mail.ru

Kryuchkov Alexander Anatolyevich - Senior Staff Scientist, Department of Agrotechnologies, Krasnoyarsk Research and Development Institute of Agriculture of FRC KRC SB RAS, Krasnoyarsk. E-mail: kralanat@yandex.ru

Исследования проводили на сорте ярового рапса Надежньй 92 в 2017-2019 ге. в Красноярской лесостепи Красноярского края. На четырех фронах изучались две схемы защиты: 1) схема защиты «Агрокемикал ДФ» (предпосевное протравливание Муссон, ВРК - 0,2 л/m, гербициды: Гурон, КЭ - 0,5 л/га, Эльф, КЭ 0,3 л/га, инсектицид: Цунами - 0,1 л/га); 2) схема защиты "Сингента» (предпосевное протравливание: Круйзер Рanc, $K C$ - 15,0 л/m, гербициды: Лонтрел Гранд, ВДГ - 0,15 ке/га, Фюзилад Форте, КЭ - 1,0 л/га, инсектицид 
Эфория, КС - 0,2 л/га). Контроль - без применения химических средств защиты растений и без применения удобрений. Применение схем защиты рапса и улучшение минерального питания растений способствовали увеличению показателей элементов структуры урожая у сорта Надежный 92: числа стручков на растении, массы семян с одного растения и массы 1000 семян. Достоверные прибавки урожайности семян от изучаемых схем защиты и применяемых видов и доз удобрений получены во всех вариантах опыта. Получены достоверные прибавки урожайности во всех вариантах применения удобрений. Наибольшая прибавка урожайности была выявлена при использовании $\mathrm{N}_{80} \mathrm{P}_{80} K_{80}$ при обеих схемах защиты. При схеме защиты «Агрокемикал ДФ» прибавка к контролю составляла 0,48 $\mathrm{m} / \mathrm{za}$, при схеме защиты "Сингента» - 0,57 m/2a. Максимальная прибавка урожайности семян была отмечена без удобрений при схеме защиты «Агрокемикал ДФ» - 0,22 m/2а.

Ключевье слова: яровой рапс, структура урожая, урожайность семян, минеральные удобрения, средства защиты растений, Красноярская лесостепь.

The aim of the research was to study the effect of mineral fertilizers and plant protection products on the elements of the crop structure and yield of spring rapeseed in the conditions of the Krasnoyarsk forest-steppe. The research problems: 1) to estimate the schemes of protection of spring rapeseed "Agrochemical of DF" and "Singenta" on the following backgrounds: without using fertilizers; N80 ammonium nitrate; ammonium nitrate + N80P80 ammophos; azofoska of N80P80K80; 2) to estimate the influence of mineral fertilizers on the systems of protection of plants," Agrochemical of $D F "$ and "Singenta". The researches were conducted on the variety of spring rapeseed Nadyozhny 92 in 2017-2019 in the Krasnoyarsk forest-steppe of Krasnoyarsk Region. On four backgrounds two schemes of protection were studied: 1. Protection scheme Agrochemical DF: pre-sowing treatment monsoon, VRK-0.2 I/t, herbicides: Huron, CE-0.5 I / hectare, Elf, CE-0.3 I / hectare, insecticide: Tsunamy - 0.1 I / hectare; 2. Syngenta protection scheme: pre-sowing treatment: kruiser Rapeseed, CS-15.0 I / t, herbicides: Lontrel Grand, VDG-0.15 kg / hectare, Fusilad Forte, CE-1.0 I / hectare, insecticide: Eyforia, CS-0.2 I / hectare. Control: without application of chemical means of protection of plants and without using fertilizers. Application of schemes of protection of rapeseed and improvement of mineral food of plants promoted the increase in indicators of elements of structure of a crop in the variety Nadyozhny 92: numbers of pods on a plant, the mass of seeds from one plant and mass of 1000 seeds. Reliable increases of productivity of seeds are received from the studied schemes of protection and the applied types and doses of fertilizers in all options of the experiment. Reliable rise of productivity in all options of use of fertilizers had been got. The greatest increase of productivity was revealed when using N80P80K80 at both schemes of protection. At the scheme of protection "Agrochemical DF" the increase to control made 0.48 t/hectare, at the scheme of protection of "Singenta" - 0.57 t/hectare. The maximum increase of productivity of seeds was noted without fertilizers at the scheme of protection "Agrochemical DF" - 0.22 t/hectare.

Keywords:spring rape, crop structure, seed yield, mineral fertilizers, plant protection means, Krasnoyarsk forest-steppe.

Введение. Яровой рапс относится к ценным масличным и кормовым культурам. Сегодня его выращиванию уделяют все больше внимания, так как рапсовое масло успешно применяется не только в пищевой, но и в химической, косметологической и энергетической промышленностях $[1,2]$. Оно также является ценным видом высокобелкового корма для животных. Кроме того, рапс играет средообразующую и фитосанитарную роль, что особенно важно для современного сельского хозяйства, для которого характерна перенасыщенность севооборотов зерновыми культурами [3]. В Красноярском крае площади под яровым рапсом стремительно растут, этому способствует стабильный спрос на семена рапса и их высокая цена в сравнении с зерновыми культурами. Так, в 2005 г. площадь под этой культурой в крае составила всего 4,1 тыс. га, а к 2017 г. увеличилась до 56,5 тыс. га, в 2019 г. достигла 144 тыс. га. Производство семян за этот же период увеличилось с 3,8 тыс. т в 2005 г. до 59,2 тыс. т в 2017 г. и до 182,7 тыс. т в 2019 г. [4, 5]. 
По биологическим особенностям яровой рапс подходит к почвенно-климатическим условиям Красноярского края. Серьезные причины низких урожаев - это несбалансированное минеральное питание, поражаемость ярового рапса широким спектром вредителей, болезней, в посевах рапса встречается большое количество видов сорных растений. Так, в 2019 г. в Красноярском крае рапс был убран лишь на площади 125,3 тыс. га по причине массового появления капустной моли, рапсовой блошки и рапсового цветоеда, а также июньской засухи, что привело к гибели посевов на площади 18,7 тыс. га.

По сравнению с другими культурами рапс предъявляет повышенные требования к обеспечению питательными веществами, прежде всего азотом, калием, фоссфором. Все мелкосемянные культуры, в том числе рапс, у которых запасы питательных веществ в семени невелики, отличаются медленным первоначальным ростом и потреблением элементов питания, в этот период они очень требовательны к высокому уровню минерального питания. Использование минеральных удобрений при выращивании ярового рапса должно проводиться с учетом региональных климатических условий, биологических особенностей растений, свойств почв [6].

Потери урожая сельскохозяйственных культур от вредителей, болезней и сорняков составляют в среднем 30-35 \%, а в годы массового распространения вредных организмов они могут достигать $60 \%$. Рапс от всходов до уборки поражается большим числом болезней, вредителей, в посевах рапса встречается широкий спектр сорных растений. Поэтому разработка комплексной системы защиты рапса от вредных организмов является важной задачей при возделывании этой культуры [7-9].

Цель исследований: изучение влияния минеральных удобрений и средств защиты растений на элементы структуры урожая и урожайность ярового рапса в условиях Красноярской лесостепи.

Задачи исследований: 1) оценить схемы защиты ярового рапса «Агрокемикал ДФ» и «Сингента» по следующим фонам: без применения удобрений; аммиачная селитра $\mathrm{N}_{80}$; аммиачная селитра + аммофос $\mathrm{N}_{80} \mathrm{P}_{80}$; азофоска $\mathrm{N}_{80} \mathrm{P}_{80} \mathrm{~K}_{80} ; 2$ 2) оценить влияние минеральных удобрений по схемам защиты растений: «Агрокемикал ДФ»; «Сингента».
Объекты и методы исследований. Полевые исследования проводились на стационаре Минино КрасНИИСХ в 2017-2019 гг. Почва опытного участка представлена черноземом выщелоченным, маломощным слабогумусированным среднедеградированным тяжелосуглинистого гранулометрического состава. Среднее содержание гумуса составляет 3,8 \%, что характеризует исследуемый чернозем как слабогумусированный (< 4 \%) с низким содержанием органического вещества. По степени кислотности почва опытного участка нейтральная. Предшественник - чистый пар. Обработка почвы типичная для зоны [10]: осенью - вспашка с оборотом пласта на 20-22 см, весной - ранневесеннее боронование по мере готовности почвы, первичная разбивка опыта, внесение удобрений, культивация, окончательная разбивка, посев, послепосевное прикатывание.

Повторность опыта - 3-кратная. Площадь

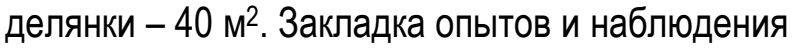
на ней проводились в соответствии с методиками государственного сортоиспытания и полевого опыта $[11,12]$. Схема опыта предусматривала четыре фона удобрений: 1) 000 (контроль без удобрений); 2) $\mathrm{N}_{80}$ (аммиачная селитра); 3) $\mathrm{N}_{80} \mathrm{P}_{80}$ (аммиачная селитра + аммофоос); 4) $\mathrm{N}_{80} \mathrm{P}_{80} \mathrm{~K}_{80}$ (азофоска).

На этих фонах изучались две схемы защиты ярового рапса в сравнении с контролем (без применения химических средств защиты растений) [13]:

1. Схема защиты «Агрокемикал ДФ»: предпосевное протравливание Муссон, ВРК - 0,2 л/т; гербициды: Гурон, КЭ - 0,5 л/га, Эльф, КЭ - 0,3 л/га, инсектицид Цунами - 0,1 л/га.

2. Схема защиты «Сингента»: предпосеваное протравливание Круйзер Рапс, КС - 15,0 л/т; гербициды: Лонтрел Гранд, ВДГ - 0,15 кг/га, Фюзилад Форте, КЭ - 1,0 л/га; инсектицид Эфория, КС - 0,2 л/га.

Для исследований использовали сорт ярового рапса Надежный 92. Масса 1000 семян - 3,34,1 г. Максимальная урожайность семян 24,1 ц/га получена на Сухобузимском ГСУ в 1995 г. Сорт 00 типа. Содержание жира в семенах - 39,8-47,6\%, эруковой кислоты в масле 0,1-1,5\%, глюкозинолатов в шроте 0,5-1,4\%. Содержание белка в зеленой массе 10,1$22,0 \%$. Вегетационный период до созревания 
семян составляет 93-114 дней. Среднеустойчив к ложной мучнистой росе, повреждается крестоцветными блошками и рапсовым цветоедом [14].

Статистическая обработка результатов проводилась с помощью пакета программ прикладной статистики Snedekor, версия 4.2 [15].

Погодные условия вегетационного периода 2017 г. характеризовались недостатком влаги в июне и июле: на 19,0 и 33,0 мм ниже нормы соответственно. Август был очень увлажненным. В июле и августе температура воздуха была чуть ниже среднемноголетних значений. Самым теплым месяцем был июнь, среднемесячное значение температуры было на $3,6{ }^{\circ} \mathrm{C}$ больше среднемноголетнего значения (табл. 1).

Таблица 1

\section{Характеристика метеорологических условий вегетационных периодов Емельяновского района в годы исследований}

\begin{tabular}{|c|c|c|c|c|c|c|c|c|}
\hline \multirow[t]{2}{*}{ Месяц } & \multicolumn{3}{|c|}{$\begin{array}{c}\text { Температура } \\
\text { воздуха, }{ }^{\circ} \mathrm{C}\end{array}$} & \multirow{2}{*}{$\begin{array}{c}\text { Среднее } \\
\text { многолетнее } \\
\text { значение }\end{array}$} & \multicolumn{3}{|c|}{$\begin{array}{l}\text { Количество } \\
\text { осадков, мм }\end{array}$} & \multirow{2}{*}{$\begin{array}{c}\text { Среднее } \\
\text { многолетнее } \\
\text { значение }\end{array}$} \\
\hline & 2017 & 2018 & 2019 & & 2017 & 2018 & 2019 & \\
\hline Май & 10,4 & 7,9 & 10,1 & 10,4 & 61,2 & 38,0 & 20,0 & 44,0 \\
\hline Июнь & 19,5 & 19,8 & 18,1 & 15,9 & 44,0 & 55,0 & 44,3 & 63,0 \\
\hline Июль & 18,8 & 17,7 & 18,8 & 18,7 & 43,0 & 41,0 & 80,0 & 76,0 \\
\hline Август & 16,5 & 18,0 & 18,2 & 15,7 & 190,0 & 30,0 & 58,0 & 67,0 \\
\hline
\end{tabular}

Вегетационный период 2018 г. характеризовался недостатком влаги. Особенно засушливыми были июль и август, количество осадков было на 35,0 и 37,0 мм ниже нормы соответственно. Среднемесячная температура июня и августа была выше среднемнолетних значений, июль, наоборот, оказался прохладным. Самым теплым месяцем был июнь, среднемесячная температура которого была на $1,8{ }^{\circ} \mathrm{C}$ больше нормы.

Май и июнь вегетационного периода 2019 г. были засушливыми, количество выпавших осадков было на 24,0 и 18,7 мм ниже среднемноголетней нормы. В июле количество осадков было выше нормы и составило 80 мм, в августе количество осадков составило 58 мм. Температурный фон вегетационного периода был близким к норме в июле и выше нормы в июне и августе (табл. 1).

Результаты исследований. В получении максимальной продуктивности культуры особая роль принадлежит параметрам элементов структуры урожая. У сорта рапса Надежный 92 наблюдалось увеличение длины растений при применении схем защиты, как «Агрокемикал ДФ», так и «Сингента», на всех удобренных фоонах.

Применение схем защиты положительно сказалось на количестве стручков с 1 растения. Увеличение количества стручков с 1 растения повлекло за собой увеличение массы семян с 1 растения при применении обеих схем защиты растений. Наибольшая масса семян с 1 растения отмечена на $\mathrm{N}_{80} \mathrm{P}_{80} \mathrm{~K}_{80}$ фоне. Применение схем защиты растений увеличило массу 1000 семян, которая больше как на контроле, так и на всех фонах удобрений. Из минеральных удобрений наибольший эффект на увеличение массы 1000 семян оказала азофоска (табл. 2).

Отмечена зависимость элементов структуры урожая ярового рапса от погодных условий лет исследований. Максимальные длина растения, число стручков, масса семян с растения и масса 1000 семян сформировались в 2017 г., минимальные - в 2018 г.

В 2018 г. применение схем защиты «Агрокемикал ДФ» и «Сингента» положительно сказалось на количестве стручков на растении, массе семян с растения и массе 1000 семян. В контрольном варианте растения в большей степени повреждались вредителями (рапсовый цветоед, рапсовый пилильщик), также наблюдалось угнетающее воздействие сорной растительности, с которой конкуренция за влагу и минеральное питание в засушливых условиях 2018 г. проявлялась наиболее выраженно. Применение минеральных удобрений увеличило количество стручков с 1 растения. Количество стручков на растениях было больше в среднем на 7,7 ( $\mathrm{N}_{80}$ фон $)-29,8$ ( $\mathrm{N}_{80} \mathrm{P}_{80} \mathrm{~K}_{80}$ фон) шт., чем на контроле без удобрений. 
Элементы структуры урожая ярового рапса в зависимости от применяемых схем защиты на разных фонах удобрений (2017-2019 гг.)

\begin{tabular}{|c|c|c|c|c|c|}
\hline & $\begin{array}{c}\text { Вариант } \\
\text { опыта }\end{array}$ & $\begin{array}{l}\text { Длина рас- } \\
\text { тения, см }\end{array}$ & $\begin{array}{c}\text { Число стручков } \\
\text { на } 1 \text { растение, шт. }\end{array}$ & $\begin{array}{l}\text { Масса семян } \\
\text { с } 1 \text { растения, г }\end{array}$ & $\begin{array}{c}\text { Macca } \\
1000 \\
\text { семян, г }\end{array}$ \\
\hline & Контроль & 99,3 & 35,2 & 2,3 & 2,5 \\
\hline 000 & «Агрокемикал ДФ» & 96,2 & 38,4 & 2,9 & 3,2 \\
\hline & Сингента & 96,2 & 41,0 & 2,9 & 3,1 \\
\hline & Контроль & 112,5 & 42,1 & 2,7 & 2,8 \\
\hline $\mathrm{N}_{80}$ & «Агрокемикал ДФ» & 113,9 & 48,5 & 3,5 & 3,2 \\
\hline & Сингента & 108,3 & 47,9 & 3,5 & 3,3 \\
\hline & Контроль & 104,9 & 42,8 & 3,2 & 3,1 \\
\hline $\mathrm{N}_{80} \mathrm{P}_{80}$ & «Агрокемикал ДФ» & 114,4 & 58,4 & 3,7 & 3.5 \\
\hline & Сингента & 116,3 & 51,2 & 3,6 & 3,6 \\
\hline & Контроль & 115,6 & 47,7 & 3,5 & 3,5 \\
\hline $\mathrm{N}_{80} \mathrm{P}_{80} \mathrm{~K}_{80}$ & «Агрокемикал ДФ» & 116,5 & 63,8 & 4,0 & 3,8 \\
\hline & Сингента & 113,0 & 61,4 & 3,9 & 3,4 \\
\hline
\end{tabular}

Увеличение количества стручков на растении повлекло за собой увеличение массы семян с 1 растения. Наибольшая масса семян была отме- чена на $\mathrm{N}_{80} \mathrm{P}_{80}$ и $\mathrm{N}_{80} \mathrm{P}_{80} \mathrm{~K}_{80}$ фонах. Мacca 1000 семян на удобренных фонах была выше в среднем на 0,3-0,8 г в сравнении с контролем.

Таблица 3

\section{Влияние схем защиты и минеральных удобрений на урожайность семян ярового рапса сорта Надежный 92}

\begin{tabular}{|c|c|c|c|c|c|}
\hline \multirow[b]{2}{*}{ Фон удобрений } & \multicolumn{5}{|c|}{ Вариант защиты растений } \\
\hline & $\begin{array}{c}\text { Контроль, } \\
\text { т/га }\end{array}$ & «Агрокемикал ДФ» & $\begin{array}{c}\text { Прибавка, } \\
\text { т/га }\end{array}$ & «Сингента» & $\begin{array}{c}\text { Прибавка, } \\
\text { т/га }\end{array}$ \\
\hline 1 & 2 & 3 & 4 & 5 & 6 \\
\hline \multicolumn{6}{|c|}{2017 г. } \\
\hline Без удобрений & 1,53 & 1,78 & $+0,25$ & 1,69 & $+0,16$ \\
\hline $\mathrm{N}_{80}$ & 1,68 & 1,86 & $+0,18$ & 2,00 & $+0,31$ \\
\hline $\mathrm{N}_{80} \mathrm{P}_{80}$ & 1,78 & 2,04 & $+0,26$ & 2,18 & $+0,40$ \\
\hline $\mathrm{N}_{80} \mathrm{P}_{80} \mathrm{~K}_{80}$ & 1,97 & 2,20 & $+0,23$ & 2,31 & $+0,35$ \\
\hline $\begin{array}{l}\text { НСР } 05: \\
\text { А (удобрения) }\end{array}$ & 0,19 & & & & \\
\hline В (вариант защиты) & 0,16 & & & & \\
\hline \multicolumn{6}{|c|}{2018 г. } \\
\hline Без удобрений & 0,72 & 0,94 & $+0,22$ & 1,00 & $+0,28$ \\
\hline $\mathrm{N}_{80}$ & 1,20 & 1,43 & $+0,23$ & 1,35 & $+0,15$ \\
\hline $\mathrm{N}_{80} \mathrm{P}_{80}$ & 1,17 & 1,34 & $+0,17$ & 1,38 & $+0,21$ \\
\hline $\mathrm{N}_{80} \mathrm{P}_{80} \mathrm{~K}_{80}$ & 1,31 & 1,45 & $+0,14$ & 1,57 & $+0,26$ \\
\hline $\begin{array}{l}\text { HCР }_{05:} \\
\text { А (удобрения) }\end{array}$ & 0,21 & & & & \\
\hline В (вариант защиты) & 0,14 & & & & \\
\hline
\end{tabular}


Окончание табл. 3

\begin{tabular}{|c|c|c|c|c|c|}
\hline 1 & 2 & 3 & 4 & 5 & 6 \\
\hline \multicolumn{6}{|c|}{2019 г. } \\
\hline Без удобрений & 1,06 & 1,25 & $+0,19$ & 1,29 & $+0,23$ \\
\hline $\mathrm{N}_{80}$ & 1,32 & 1,48 & $+0,16$ & 1,60 & $+0,28$ \\
\hline $\mathrm{N}_{80} \mathrm{P}_{80}$ & 1,34 & 1,61 & $+0,27$ & 1,67 & $+0,33$ \\
\hline $\mathrm{N}_{80} \mathrm{P}_{80} \mathrm{~K}_{80}$ & 1,49 & 1,74 & $+0,25$ & 1,82 & $+0,33$ \\
\hline $\begin{array}{l}\text { НСР } 05: \\
\text { А (удобрения) }\end{array}$ & 0,17 & & & & \\
\hline В (вариант защиты) & 0,12 & & & & \\
\hline \multicolumn{6}{|c|}{ 2017-2019 гг. } \\
\hline Без удобрений & 1,10 & 1,32 & $+0,22$ & 1,33 & $+0,23$ \\
\hline $\mathrm{N}_{80}$ & 1,40 & 1,59 & $+0,19$ & 1,65 & $+0,25$ \\
\hline $\mathrm{N}_{80} \mathrm{P}_{80}$ & 1,43 & 1,66 & $+0,23$ & 1,74 & $+0,31$ \\
\hline $\mathrm{N}_{80} \mathrm{P}_{80} \mathrm{~K}_{80}$ & 1,59 & 1,80 & $+0,21$ & 1,90 & $+0,31$ \\
\hline $\begin{array}{l}\mathrm{HCP}_{05:} \\
\text { А (удобрения) }\end{array}$ & 0,18 & & & & \\
\hline В (вариант защиты) & 0,14 & & & & \\
\hline
\end{tabular}

При применении минеральных удобрений на изучаемых фонах в 2019 г. количество стручков на растениях было больше в среднем на 6,1 ( $\mathrm{N}_{80}$ фон) - 15,1 ( $\mathrm{N}_{80} \mathrm{P}_{80} \mathrm{~K}_{80}$ фон) шт., чем на контроле без удобрений. Наибольшая масса семян с 1 растения и масса 1000 семян отмечена в четвертом варианте опыта, на $\mathrm{N}_{80} \mathrm{P}_{80} \mathrm{~K}_{80}$ фоне. В целом можно констатировать значительное улучшение показателей структуры урожая ярового рапса от применения минеральных удобрений и средств защиты растений.

По результатам полевого опыта в 2017 г. получены достоверные прибавки урожайности семян рапса сорта Надежный 92 от обеих схем защиты за исключением схемы защиты «Сингента» без удобрений (см. табл. 3). Также отмечено значительное увеличение урожайности семян рапса от применения минеральных удобрений. Разница в увеличении урожайности семян рапса между двумя изучаемыми схемами защиты статистически незначительна, что показывает их близкую эфффективность. Наибольшая прибавка урожайности семян рапса исследуемых схем защиты была отмечена на $\mathrm{N}_{80} \mathrm{P}_{80}$ фоне: 0,26 т/га на схеме защиты «Агрокемикал ДФ» и 0,40 т/га на схеме защиты «Сингента».

Применяемые схемы защиты рапса показали достоверные прибавки урожайности семян и в 2018 г. Погодные условия года способствовали развитию вредителей, количество сорных рас- тений было больше в сравнении с 2017 г. Избавление от сорняков, вредителей при помощи инсектицидов и гербицидов, входящих в баковые смеси изучаемых схем защиты рапса, способствовало снижению неблагоприятного воздействия на растения рапса и, как следствие, увеличению урожайности. Наибольшие прибавки семян рапса в 2018 г. были отмечены при схеме защиты «Агрокемикал ДФ» на $\mathrm{N}_{80}$ фоне 0,23 т/га, и 0,28 т/га - при схеме защиты «Сингента» (вариант опыта без удобрений).

В 2019 г. максимальные прибавки урожайности семян у сорта Надежный 92 наблюдались при схеме защиты «Сингента» на $\mathrm{N}_{80} \mathrm{P}_{80}$ и $\mathrm{N}_{80} \mathrm{P}_{80} \mathrm{~K}_{80}$ фонах - 0,33 ц/га, при схеме защиты «Агрокемикал ДФ» на $\mathrm{N}_{80} \mathrm{P}_{80}$ фоне - 0,27 т/га в сравнении с контролем без применения средств защиты.

\section{Выводы}

1. Применение исследуемых схем защиты ярового рапса и улучшение минерального питания растений способствовало увеличению показателей элементов структуры урожая у сорта Надежный 92. Растения рапса положительно отреагировали увеличением числа стручков на растении, массы семян с одного растения и массы 1000 семян. Наибольший эфрфект наблюдался при применении обеих схем защиты рапса на удобренных фонах. 
2. По результатам исследований представленные схемы защиты ярового рапса показали высокую эффрективность и успешно боролись с сорными растениями и вредителями в посевах, снимая неблагоприятное воздействие вредных организмов. Достоверные прибавки урожайности семян от изучаемых схем защиты получены на всех исследуемых фонах.

В среднем за 2017-2019 гг. прибавки урожайности без применения удобрений составили 20 и 17,3 \% при схеме защиты «Агрокемикал ДФ» и «Сингента» соответственно. На фоне $\mathrm{N}_{80}$ размер прибавок урожайности составлял 13,6 и $15,2 \%$, применение аммиачной селитры с аммофосом в дозе $\mathrm{N}_{80} \mathrm{P}_{80}$ обеспечивало прибавки 16,1 и 17,8 \%; использование азофроски в дозе $\mathrm{N}_{80} \mathrm{P}_{80} \mathrm{~K}_{80}$ позволяет получить прибавки урожайности семян ярового рапса в размере 13,2 и $18,2 \%$ соответственно.

3. Изучение влияния удобрений позволило установить достоверные прибавки во всех вариантах применения удобрений. Наибольшая прибавка урожайности получена при использовании $\mathrm{N}_{80} \mathrm{P}_{80} \mathrm{~K}_{80}$ при обеих схемах защиты. При схеме защиты «Агрокемикал ДФ» прибавка к контролю (неудобренному фону) составляла 0,48 т/га, при схеме защиты «Сингента» 0,57 т/га.

\section{Литература}

1. Казанцев В.П. Рапс, сурепица и редька масличная в Сибири. Новосибирск: ВАСХНИЛ. Сиб. отд-ние, 2001. 116 с.

2. Федотов В.А. Рапс в России. М.: Агролига России, 2008. 336 с.

3. Шnаaр Д. Рапс и сурепица. M.: DLV Агродело, 2007.320 с.

4. Олейникова Е.Н., Янова М.А., Пьжикова Н.И. и др. Яровой рапс - перспективная культура для развития агропромышленного комплекса Красноярского края // Вестник КрасГАУ. 2019. № 1. С. 74-80.

5. Министерство сельского хозяйства и торговли Красноярского края. Статистическая информация. URL: http://krasagro.ru/ pages/info/stat (дата обращения: 13.01.2020).

6. Волошин Е.И., Аветисян А.Т. Руководство по удобрению капустных культур / Краснояр. гос. аграр. ун-т. Красноярск, 2017. 28 с.
7. Федоренко В.П., Секун Н.П., Марков И.Л. и др. Защита рапса // Защита и карантин растений. 2008. № 4. С. 34-37.

8. Фолькер Х.П. Рапс. Болезни. Вредители. Сорные растения. Минск: Дивимедиа, 2012. 196 c.

9. Возделывание ярового рапса в Красноярском крае: науч.-практ. пособие / СибНИИ кормов. Новосибирск, 2016. 48 с.

10. Система земледелия Красноярского края на ландшафтной основе: руководство. Красноярск, 2015. 591 c.

11. Федин М.А. Методика государственного сортоиспытания. М.: Колос, 1985. 263 с.

12. Доспехов Б.А. Методика полевого опыта. М.: Агропроиздат, 1985. $316 \mathrm{c.}$

13. Список пестицидов и агрохимикатов, разрешенных к применению на территории Российской Федерации. М., 2019. 848 с.

14. Характеристики сортов растений, включенные в государственный реестр селекционных достижений, допущенных к использованию по Красноярскому краю в 2019 году. Красноярск, 2019. - 543 с.

15. Сорокин О.Д. Прикладная статистика на компьютере. Новосибирск, 2004. 162 с.

\section{Literatura}

1. Kazancev V.P. Raps, surepica i red'ka maslichnaja v Sibiri. Novosibirsk: VASHNIL. Sib. otd-nie, 2001. $116 \mathrm{~s}$.

2. Fedotov V.A. Raps v Rossii: monografija. M.: Agroliga Rossii, 2008. $336 \mathrm{~s}$.

3. Shpaar D. Raps i surepica. M.: DLV Agrodelo, 2007. $320 \mathrm{~s}$.

4. Olejnikova E.N., Janova M.A., Pyzhikova N.I. i dr. Jarovoj raps perspektivnaja kul'tura dlja razvitija agropromyshlennogo kompleksa Krasnojarskogo kraja // Vestnik KrasGAU. 2019. № 1. S. 74-80.

5. Ministerstvo sel'skogo hozjajstva i torgovli Krasnojarskogo kraja. Statisticheskaja informacija. URL: http://krasagro.ru/pages/ info/stat (data obrashhenija: 13.01.2020).

6. Voloshin E.I., Avetisjan A.T. Rukovodstvo po udobreniju kapustnyh kul'tur / Krasnojar. gos. agrar. un-t. Krasnojarsk, 2017. 28 s. 
7. Fedorenko V.P., Sekun N.P., Markov I.L. i dr. Zashhita rapsa // Zashhita i karantin rastenij. 2008. № 4. S. 34-37.

8. Fol'ker H.P. Raps. Bolezni. Vrediteli. Sornye rastenija. Minsk: Divimedia, 2012. 196 s.

9. Vozdelyvanie jarovogo rapsa v Krasnojarskom krae: nauch.-prakt. posobie / SibNII kormov. Novosibirsk, 2016. $48 \mathrm{~s}$.

10. Sistema zemledelija Krasnojarskogo kraja na landshaftnoj osnove: rukovodstvo. Krasnojarsk, 2015. $591 \mathrm{~s}$.

11. Fedin M.A. Metodika gosudarstvennogo sortoispytanija. M.: Kolos, 1985. $263 \mathrm{~s}$.
12. Dospehov B.A. Metodika polevogo opyta. M.: Agroproizdat, 1985. - $316 \mathrm{~s}$.

13. Spisok pesticidov i agrohimikatov, razreshennyh $k$ primeneniju na territorii Rossijskoj Federacii. M., 2019. 848 s.

14. Harakteristiki sortov rastenij, vkljuchennye v gosudarstvennyj reestr selekcionnyh dostizhenij, dopushhennyh $k$ ispol'zovaniju po Krasnojarskomu kraju v 2019 godu. Krasnojarsk, 2019. $543 \mathrm{~s}$.

15. Sorokin O.D. Prikladnaja statistika na komp'jutere. Novosibirsk, 2004. $162 \mathrm{~s}$. 